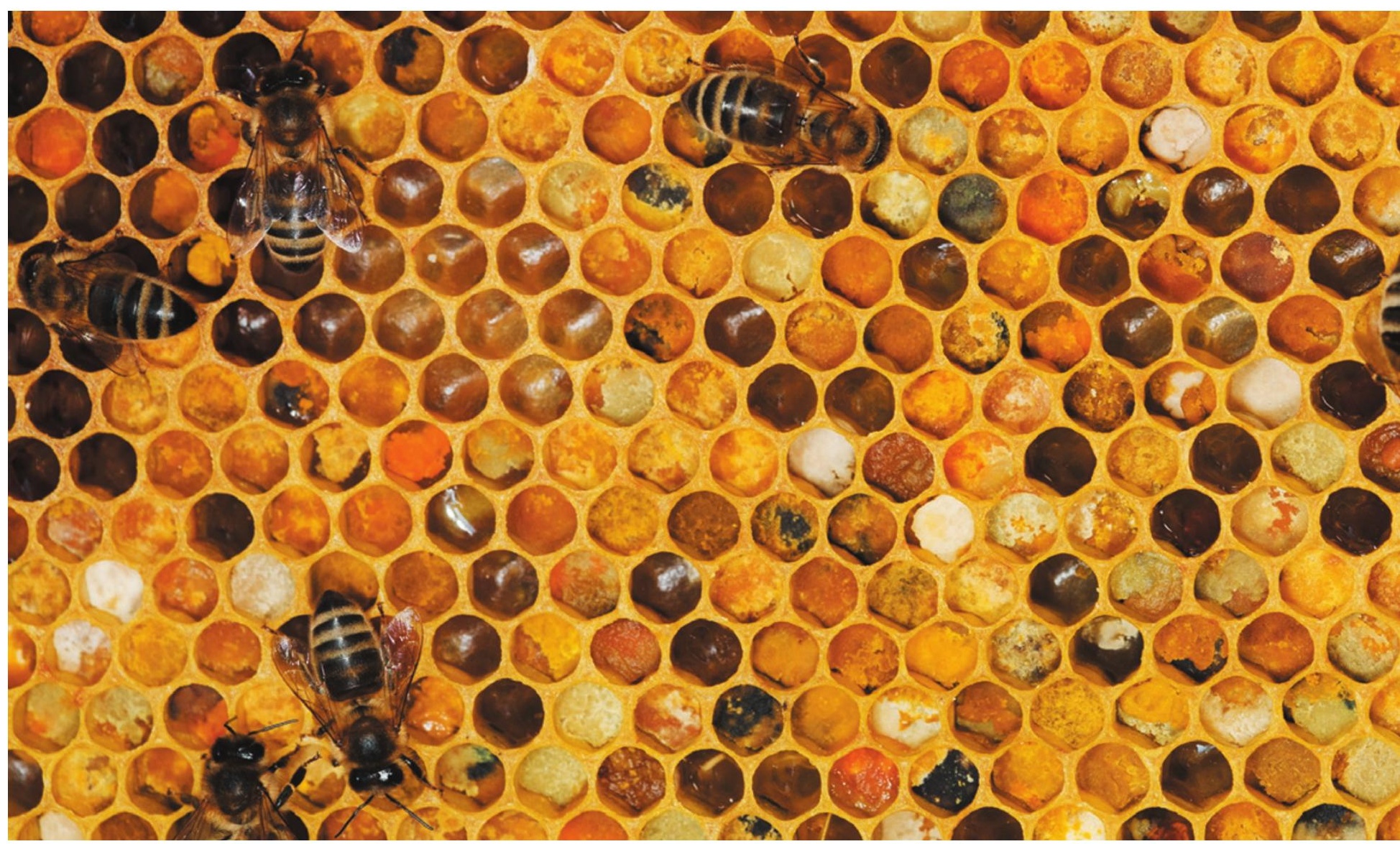

Honeybee (Apis mellifera) workers busy themselves on their comb.

\title{
ENTOMOLOGY
}

\section{The apian way}

\section{Mark Winston revels in a deep exploration of the honeybee colony and its organization.}

I $\mathrm{n}$ his 1901 book The Life of the Bee, philosopher, poet and Symbolist Maurice Maeterlinck mused over the "spirit of the hive". How, he wondered, do many thousands of social insects organize themselves into a cooperating colony? In the fascinating The Spirit of the Hive, eminent bee geneticist Robert Page demonstrates how science is answering that key question.

The book - representing a lifetime's research for Page - illustrates just how far we have come in dissecting and reconstructing the myriad factors responsible for colony-level functions. Page stands on the shoulders of, and acknowledges, bee geneticist Harry Laidlaw, who unravelled many basic aspects of honeybee genetics and mating behaviour. But Page chronicles the expansion of methodologies over many decades, from behavioural and hormonal analyses to neurochemistry, and eventually DNA sequencing. We also learn how researchers working with honeybees pioneered many techniques. An example is genetic mapping with quantitative trait loci, which can identify the multiple linked genes that determine complex behaviours such as pollen foraging.

The Spirit of the Hive hinges on the simple question of what causes honeybees to collect more or less pollen and nectar. Individual worker bees were once viewed as behaviourally identical, but Page and others have demonstrated that there is significant variation in individuals' responses to stimuli that determine the level of nectar and pollen foraging, such as the amount of pollen stored in the nest. Furthermore, each queen mates with an average of 12 drones, whose sperm mixes in her sperm sac. Each colony's worker bees thus present a distinctive mix of genetically influenced tendencies for foraging.

Page then tackles how individual bees with differing genetic backgrounds create flexibility in the colony to regulate tasks - including pollen, nectar and water collection, defence and the removal of dead bees from the nest

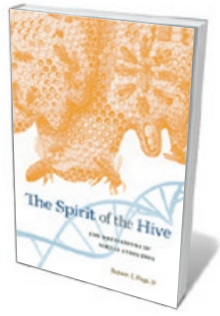

The Spirit of the Hive: The Mechanisms of Social Evolution ROBERT E. PAGE Harvard University Press: 2013. genotype explains just 8-25\% of behavioural variance, and usually closer to $8 \%$. This is a comforting concept for those who prefer nurture to nature.

The Spirit of the Hive is pitched at Page's fellow evolutionary biologists, and in places requires some understanding of Boolean 


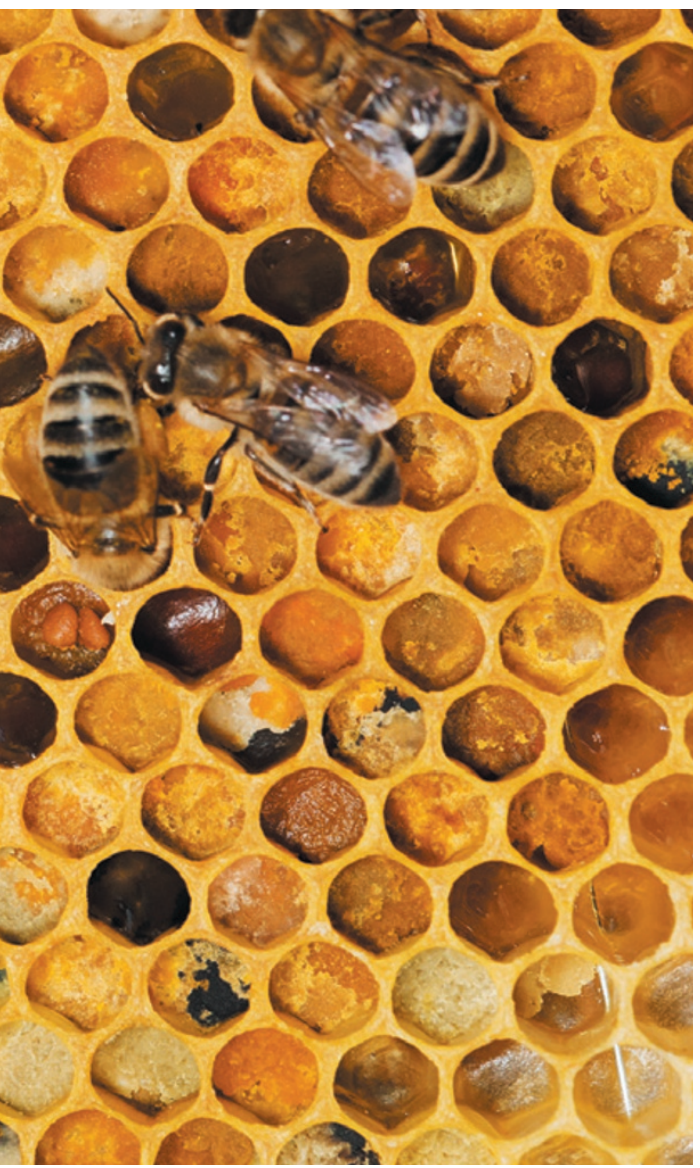

¿ logic, binary behaviour and basic genetics. But the book is at its best when Page uses story and description rather than models and mathematics. He clearly has considerw able affection for his co-workers and for bees, and provides marvellous glimpses into how research is conducted. He opens is that world to us through descriptions of his own elegant experiments, such as those exploring the genetic component of pollen collection.

I would have liked to hear more about the people he worked with and his relationship with his insects after so many decades in the field. Page finishes abruptly, with a too-short chapter that brings us back to Maeterlinck's The Life of the Bee. I missed the soaring language of the poet here, which would have beautifully completed the circle - for instance, Maeterlinck's description of the hive as containing "the enigma of intellect, of destiny, will, aim, means, causes; the incomprehensible organization of the most insignificant act of life".

Still, Page's book is a delightful example of how one dedicated career in science can dramatically deepen and broaden our perceptions of the world around us.

Mark L. Winston is academic director and a fellow of Simon Fraser University's Centre for Dialogue in Vancouver, Canada. e-mail:winston@sfu.ca

\section{Books in brief}

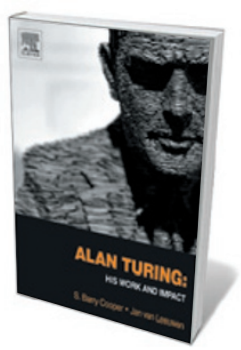

Alan Turing: His Work and Impact

Edited by S. Barry Cooper and Jan van Leeuwen ELSEVIER (2013)

The new testament of computer science has come, 101 years after the birth of founding prophet Alan Turing. It took 70 renowned evangelists from all walks of science and philosophy to put the polymath's words in context and dissect his living impact on pure maths, physics, biology, engineering, banking, metaphysics and beyond. How big is the incomputable universe? Can digital machines think? Do daisies emerge from pure chemistry? If your soul craves answers to such questions, this is your new bible.

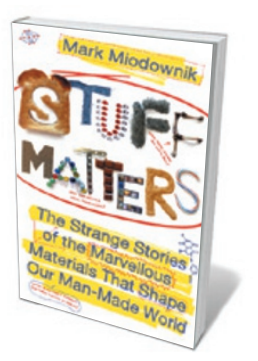

Stuff Matters: The Strange Stories of the Marvellous Materials that Shape Our Man-Made World

Mark Miodownik VIKING (2013)

Today's materials vie with our wildest imaginings, from

two-dimensional graphene to aerogel - made up of $99.8 \%$ air, resembling "solid smoke" and created by NASA to gather space dust. In this homage to materiality, Mark Miodownik tells us why we should care about stuff. The materials specialist traces his obsession back to a violent childhood epiphany when, stabbed with a razor blade, he woke to the wonders of steel. Here, we too are jolted into a new consciousness of the made world's multiple facets.

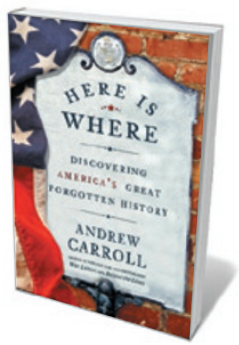

Here Is Where: Discovering America's Great Forgotten History Andrew Carroll CROWN ARCHETYPE (2013)

From Plymouth Colony to Gettysburg, Pennsylvania, hotspots of US history are well and truly mapped. Yet 'off-piste' places with scientific importance abound, as historian Andrew Carroll reveals on this road trip around forgotten America. He ably guides us through triumphs and horrors: the Oregon caves where the continent's oldest human DNA was radiocarbon dated; California's Sonoma Developmental Center, where thousands were sterilized in the name of eugenics; the Massachusetts cherry tree where rocketeer-to-be Robert Goddard dreamed of interplanetary travel; and much more.

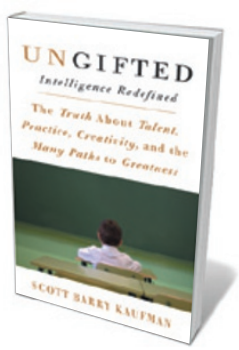

Ungifted: Intelligence Redefined

Scott Barry Kaufman BASIC Books (2013)

Hearing difficulties and a low IQ score left the young Scott Barry Kaufman labelled learning disabled. Now a cognitive psychologist, he charts his journey from judgement by metrics to a deeper understanding of human intelligence. Gathering research on areas from nature-nurture interplay to the psychology of motivation, he presents a convincing "theory of personal intelligence". But what emerges most clearly is how all children — gifted, disabled or simply humming with untapped abilities — need a fine-tuned, holistic education to shine in their own extraordinary ways.

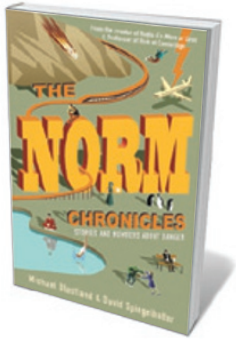

The Norm Chronicles: Stories and Numbers About Danger Michael Blastland and David Spiege/halter PROFILE BOOKS (2013) Writer Michael Blastland and risk specialist David Spiegelhalter offer a fresh take on the hot topic of risk. They explore chance and probability through the characters Prudence, Norm and Kelvin, who represent the spectrum of risk-taking behaviour. Even as the authors offer innovative tools for measuring acute and chronic risk, they remind us that data have limits. If you want to know the odds on shrinking your lifespan by imbibing that second glass of wine or being hit by an asteroid, take a gamble on this book. Barbara Kiser 